LA-7785-MS

Informal Report

UC-25

Iseued: April 1979

\title{
The Eectronic Configurations and Energies in Some Thermodynamically Correlated Laves Compounds
}

George M. Campbell
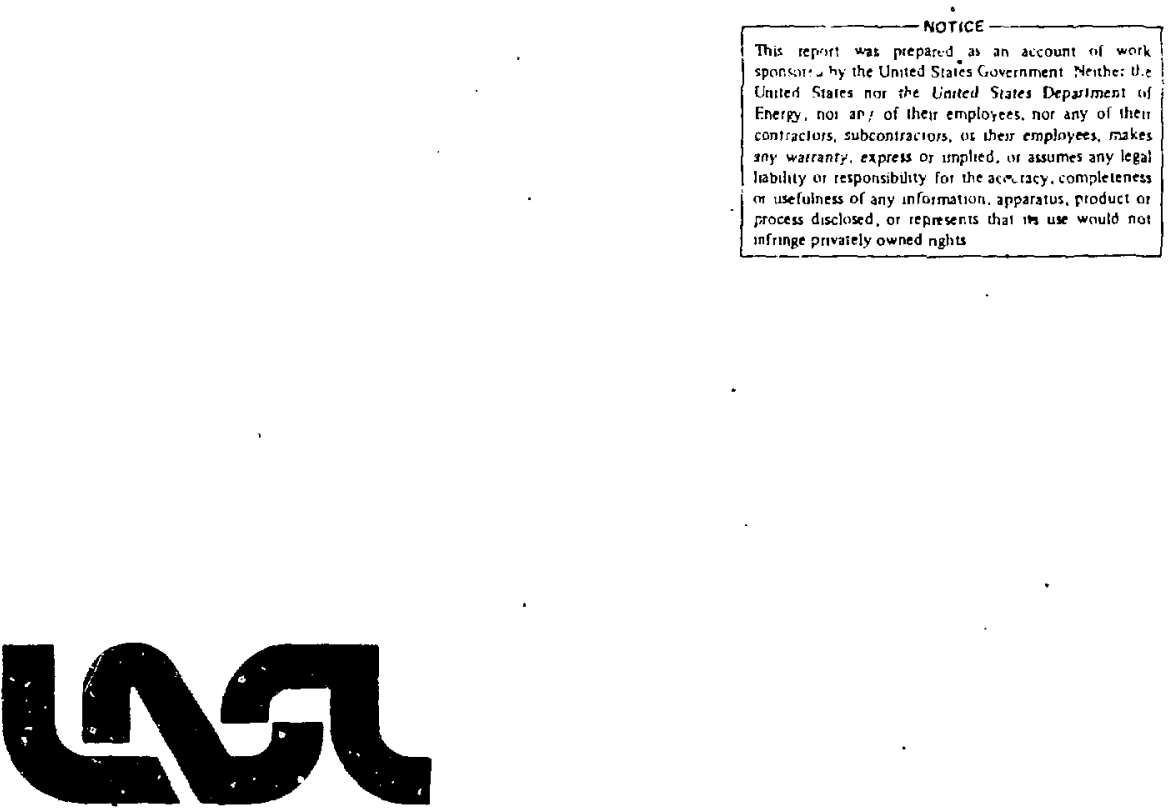


\title{
THE ELECTRONIC CONFIGURATIONS AND ENERGIES IN SOME THERMODYNAMICALLY CORRELATED LAVES COMPOUNDS
}

\author{
by
}

George M. Campbell

\section{ABSTRACT}

The known electronic configurations of simple elements in Laves compounds are correlated with those of the more complex systems to determine their electronic configurations and gaseous state prumotion energies.

\section{INTRODUCTION}

The formation of intermetallic compounds is usually accompanied by a size change of the atoms involved in going from their pure solid state to the alloy form. In $A B_{2}$ type Laves compounds the structural features permit unambiguous determination of interatomic distance in the compound. The radius ratio $R_{A} / R_{B}$ in these compounds is very close to 1.225 . A linear correlation of $R_{A} / R_{B}$ with the heat of formation, $\Delta H_{f}^{0}$ was found to occur between metals of equal valence. ${ }^{1,2}$ Some compounds such as $\mathrm{UAT}_{2}$ and $\mathrm{PuAl}_{2}$ with radius ratios of 1.077 and 1.064 seem to lie below the limit where this type of compound should be stable.

Zuchariasen ${ }^{3}$ has corielated the unalloyed metallic radius with the number of bonding electrons in a given element as a means of deducing the metallic valence for the element. In this paper, use wiil be made of these radii to show the relationship between heat of formation, $\Delta H_{f}^{0}$, and cohesive energy, $E_{c, u h}{ }$. It will be shown that this relationship can be used to determine electronic configurations and gaseous state promotion energies. 
II. CORRELATION OF $\triangle H_{f}^{0}$ VS $R_{A} / R_{B}$ FOR COMPOUNDS THAT HAVE UNALLOYED METALS OF UNEQUAL VALENCE

Experimental evidence ${ }^{4}$ indicates that metals capable of valence change increase valence when alloyed with metals of higher valence and decrease it when alloyed with a metal of lower valence. The compounds $\mathrm{UAl}_{2}, \mathrm{PUAl}_{2}, \mathrm{CeAl}_{2}, \mathrm{YbAl}_{2}$ and $\mathrm{NaCd}_{2}$ are examples of Laves compounds which have unequal valence before alloy formation. The metals $U, P u, C e$ ard perhaps $Y b$ are believed to be able to change valence by promoting $f$ electrons. We will consider all non-f electrons as valence electrons. Since $A 1$ is unlikely to differ from a valence of 3 we will assume that $U, \mathrm{Pu}$ and $\mathrm{Ce}$ achieve a valence of 3 when alloyed with $\mathrm{Al}$. The radius ratios for these compounds with valence 3 are given in Table $I$. It will be noted in Figure 1 that the $\Delta H_{f_{298}}^{0}$ values plotted as a function of $R_{A} / R_{B}$ ail lie below the line which correlates the rare earth-aluminum compounds. It will also be noted that the difference is exactly equal to the heat of iusion, $\Delta H_{m}$, of the $A$ metal in each case. A test of plotting $\mathrm{YbAl}_{2}$ with $\mathrm{Yb}$ as divalent or as trivalent leaves no doubt that the perfect fit requires $Y b$ to be divalent. Other evidence ${ }^{5}$ indicates that it is either divalent or mostly divalent at $298 \mathrm{~K}$. In the comppound $\mathrm{NaCd}_{2}$ neither metal is likely to have more than one valence. It can be seen from Figure 1 that the $\Delta H_{f_{29} \text { a }}^{0}$ value for this compound differs from the line correlating the alkali earth-magnesium compounds by exactly the heat of fusion of $\mathrm{Na}$.

The rare earth-aluminum compounds whose metals have equal valence at room temperature have $\Delta H_{f_{298}}$ value :iven by

$$
-\Delta H_{f_{298}}^{2}=560.37-389.15 R_{A} / R_{B} \quad k J / g \text {-atom. }
$$

All other compounds in this group are given by

$$
-\Delta H_{f_{298}}^{0}=-\Delta H_{f_{29 \theta}}^{2}+\Delta H_{f}^{3},
$$

where $\Delta H_{f}^{3}$ is the heat of fusion of the A metals, Ce, Pu, $U$ and $Y b$.

The line correlating the alkali metal-magnesium compounds is given by

$$
-\Delta H_{f_{298}^{2}}^{2}=97.48-67.91 R_{A} / R_{B} k J / g \text {-atom }
$$


TABLE I

COMPARISON OF CALCULATCD AND EXPERIMENTAL HEATS OF FORMATION

\begin{tabular}{|c|c|c|c|c|c|c|}
\hline Curipound & $\begin{array}{c}\text { Valence } \\
\text { of } A\end{array}$ & $R_{A / R_{B}}$ & $\begin{array}{l}\Delta H_{m} \text { of } A \\
k J / g-a t .\end{array}$ & $\begin{array}{l}-\Delta H_{f_{2}}^{0} \\
k J / g- \\
\mathrm{Ca} / \mathrm{C} .\end{array}$ & ExptT. & Ref \\
\hline $\mathrm{CeAl}_{2}$ & 3 & 1.287 & 5.18 & 54.4 & 54.4 & 12 \\
\hline LaA ${ }_{2}$ & 3 & 1.311 & - & 50.2 & 50.2 & 13 \\
\hline $\mathrm{PrAl}_{2}$ & 3 & $1.27 ?$ & - & 63.4 & 62.8 & 14 \\
\hline $\mathrm{PuAl}_{2}$ & 3 & 1.306 & 3.93 & 48.2 & 47.4 & 15 \\
\hline $\mathrm{UAl}_{2}$ & 3 & 1.327 & 12.95 & ו. & 31.1 & 16 \\
\hline $\mathrm{YaAl} \mathrm{I}_{2}$ & 2 & $1.35 \%$ & 7.66 & 25.4 & 25.7 & 17 \\
\hline $\mathrm{CaCd}_{\text {c }}$ & 2 & 1.260 & - & 36.1 & 41.1 & 18 \\
\hline $\mathrm{Pig} \mathrm{Z} \mathrm{n}_{2}$ & 2 & 1.149 & - & 17.6 & 17.9 & 11 \\
\hline $\mathrm{PuFe}_{2}$ & 6 & 1.198 & - & 16.6 & 16.6 & 1 \\
\hline $\mathrm{PuOs}_{2}$ & 6 & 1.132 & - & 5.2 & 4.9 & 1 \\
\hline $\mathrm{PuRu}_{2}$ & 6 & 1.143 & - & 7.1 & 7.4 & 1 \\
\hline $\mathrm{UFe}_{2}$ & 5 & 1.208 & - & 18.3 & 20.6 & 2 \\
\hline $\mathrm{BaMg}_{2}$ & 2 & 1.396 & - & 2.7 & 2.1 & 19 \\
\hline $\mathrm{CaMg}_{2}$ & 2 & 1.233 & - & 1.3 .7 & 13.4 & 19 \\
\hline $\mathrm{NaCd}_{2}$ & 1 & 1.219 & 2.6 & 11.0 & 11.3 & 10 \\
\hline $\mathrm{SrMg}_{2}$ & 2 & 1.343 & - & 6.3 & 7.1 & 19 \\
\hline
\end{tabular}

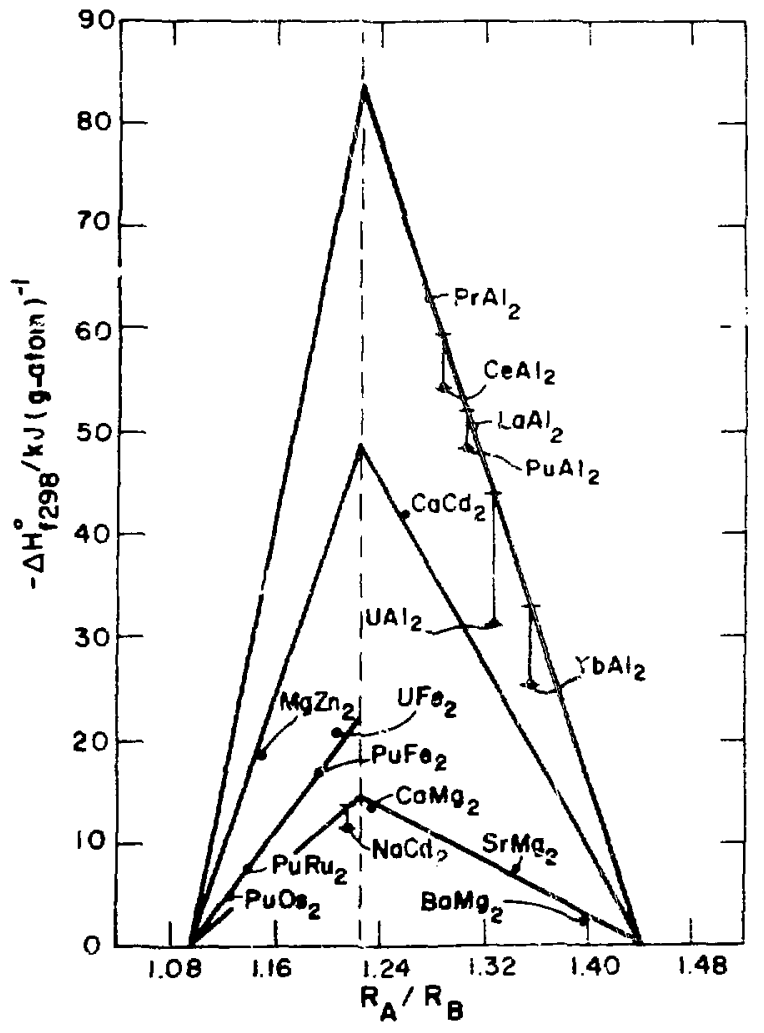

Fig. 1. Heat of formation vs geometry factor for some $A B_{2}$ Laves compounds.

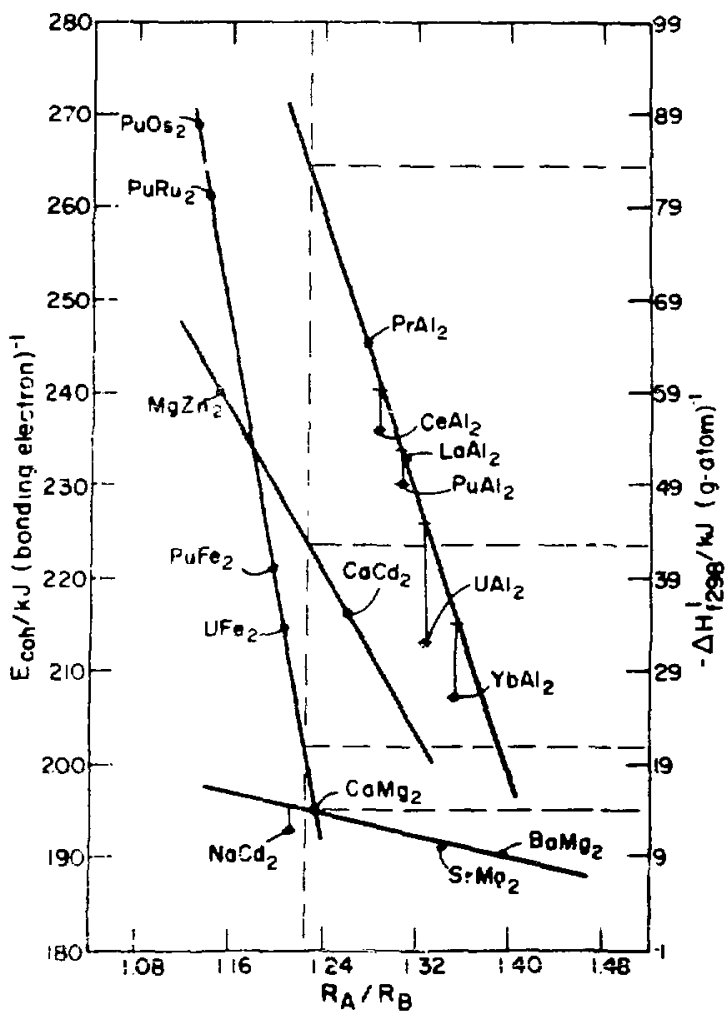

Fig. 2. Cohesive enargy vs geometry factor for some $\mathrm{AB}_{2}$ Laves compounds. 
Sinse a break occurs in the correlation line at $R_{A} / R_{B}=1.225$ we will refer to the $\Delta H$ value at this point as $\Delta H_{f_{298}^{1}}^{1}$. The correlation line for $\mathrm{CaMg}_{2}$, $\mathrm{BaMg}_{2}$ has a $\Delta \mathrm{H}_{\mathrm{f}_{298}^{1}}^{1}$ value of $-14.3 \mathrm{~kJ} / \mathrm{g}$-atom. The correspondiris line connecting this point and $\Delta H_{f_{298}}=0$ t. $R_{A} / R_{B}=1.1$ is given by

$$
-\Delta H_{f_{293}^{2}}^{2}=-120.32+109.89 R_{A} / R_{B} k J / g \text {-atom }
$$

The $\Delta H_{f_{298}}^{0}$ for $\mathrm{NaCd}_{2}$ is given by Eq. 2 with $\Delta H_{f}^{3}$ the heat of fusion of Na.

The heat of formation may be viewed as consisting of three parts. The first term $\Delta H_{f}^{l}$ resulting from cherical properties of the two metals is increased to $\Delta H_{f}^{2}$ to meet structural size requirements. A third term $\Delta H_{f}^{3}$ is related to an electronic configurational change required to accommodiate unequal vialences.

\section{DETERMINATION OF $\triangle H_{f}^{1}$ FROM COHESIVE ENERGIES}

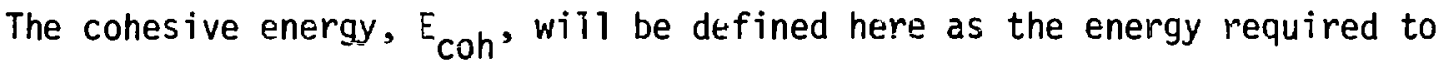
atomize a neutral element and promote it to a particular electronic configuration in the gaseous state. Brewer has tabulated cohesive energies for a large number of elements and electronic configurations ${ }^{6}$ and lists promotion energies for actinides and lanthanides. ${ }^{7}$ All $E_{\text {coh }}$ values not calculated from correlated $\triangle H_{f}^{l}$ values in the present paper will be taken from these two references. Heats of fusion were taken from Hultgren ei al. ${ }^{8,9}$ The total cohesive energy will be calculated by the relation.

$$
E_{\text {coh }}^{t}=\Delta H_{v, 0}+E_{p}
$$

where $\Delta H_{v, 0}$ is the heat of vaporization of the element at $0 \mathrm{~K}$ and $E_{p}$ is the promotion energy from the gaseous griund state to the electronic configuration of interest. $E_{\text {coh }}$ will be the symbol for the cohesive energy per bonding electron, determined by dividing the tota? cohe ive energy, $\mathrm{E}_{\mathrm{coh}}^{\mathrm{t}}$, by the number of bonding electrons. The cohesive energy per boiding electron of the compound will be calculated for the $\mathrm{AB}_{2}$ laves compound frolil

$$
E_{\operatorname{con}}\left(A B_{2}\right)=1 / 3 E_{\operatorname{coh}}(A)+2 / 3 E_{\operatorname{coh}}(B) .
$$


A. Cohesive Energies for Correlated Group I Compounds

The cohesive energies for the compounds $\mathrm{BaMg}_{2}, \mathrm{CaMg}_{2}, \mathrm{NaCd}_{2}$ and $\mathrm{SrMg}_{2}$ are given in Table II. There seem to be little choice of electronic configuration for the first and third groups of correlated compounds. The least squares line which fits the compounds $\mathrm{BaMg}_{2}, \mathrm{SrMg}_{2}$ and $\mathrm{CaMg}_{2}$ is

$$
E_{\text {coh }}=232.2-30.32 R_{A} / R_{B} k J / \text { eiectron - }
$$

Thi value for $\mathrm{NaCd}_{2}$ differs from this 1 ine as seen in Figure 2 by $\Delta H_{f}^{3}(\mathrm{Na})$, the heat of fusion of $\mathrm{Na}$. We see that if the $\Delta \mathrm{H}_{f}^{1}$ values are proportional to $E$ coh then

$$
-\Delta H_{f}^{1}=E_{c o h}^{1}-180.7 \mathrm{~kJ} / \mathrm{g} \text {-atom, }
$$

where $E_{\text {coh }}^{l}=E_{\text {coh }}$ at $R_{A} / R_{B}=1.225$.

B. Cohesive Energies for Correlated Group II Compounds

In order for cohesive energies of the compounds $\mathrm{PuOs}_{2}, \mathrm{PuRu}_{2}, \mathrm{PuFe}_{2}$ and $\mathrm{UFe}_{2}$ as well as the value of $\Delta \mathrm{H}_{f_{z 98}}^{l}$ to be on the same line, the cohesive energy of Pu must be $451 \mathrm{~kJ} / \mathrm{electron}$. When compared to the possible electronic configurations and their promotion energies for $P u$, it seems likely that the $5 f^{2} 6 d^{4} 7 \mathrm{~s} 7 \mathrm{p}$ configuration which allows electrons to be shared with the $3 d^{6} 454 p$ configuration of iron at the $d, s$ and $p$ levels is tris correct one. Each metal is hexavalent.

The line describing the cohesive energies for these compounds is

$$
E_{\text {coh }}=1082 .-718.4 R_{A} / R_{B} \text { kJ/electron. }
$$

At $R_{A} / R_{B}=1.225, E_{\text {coh }}^{l}=202 \mathrm{~kJ} /$ electron.

From Eq. 8, $\Delta H_{f_{298}^{l}}^{l}=-21.3 \mathrm{~kJ} / \mathrm{g}$-atcm.

The heats of formation for this group are given by

$$
-\Delta H_{f_{298}}^{0}=-190.5+172.9 R_{A} / R_{B} \mathrm{~kJ} / \mathrm{g} \text {-å̃om } .
$$


TABLE II

ELECTRONIC CONFIGURATION AND CORESIVE ENERGIES IN THE GASEOUS

VALENCE STATE AT $\$ KOR CORRELATED GROUP I

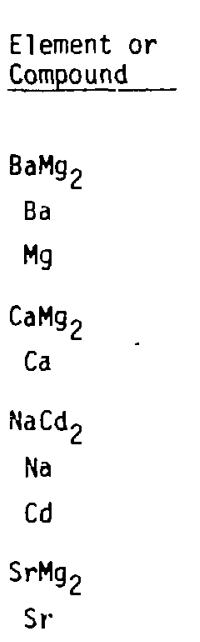

Electronic Configuration
in the Compound
-
$5 s 6 p$
$3 s 3 p$
-
$454 p$
-
3
$5 s 5 p$
-
$5 s 5 p$

\begin{tabular}{|c|c|}
\hline \multicolumn{2}{|c|}{$\begin{array}{c}\text { Energy Per } \\
\text { Bonding Electron } \\
\mathrm{kJ}\end{array}$} \\
\hline Ret. 6 & Calc. \\
\hline 190.0 & 190.0 \\
\hline 163.0 & - \\
\hline 203.0 & - \\
\hline 195.0 & 195.0 \\
\hline 178.0 & - \\
\hline 193.0 & 193.0 \\
\hline 108.0 & - \\
\hline 236.0 & - \\
\hline 0 & 191.0 \\
\hline 167.0 & - \\
\hline
\end{tabular}

TABLE III

ELECTRONIC CONFIGURATION AND COHFSIVE ENERGIES IN THE GASEOUS

VALENCE STATE AT $K$ FOR CORFELLTTED GROUP II AND III

Element or

Compound

$\mathrm{PuFe}_{2}$
$\mathrm{Pu}$
$\mathrm{Fe}$
$\mathrm{PuOs}_{2}$
$\mathrm{Ps}$
$\mathrm{PuRu}_{2}$
$\mathrm{Fu}$
$\mathrm{UFe}_{2}$
$\mathrm{U}$
$\mathrm{Fe}$
$\mathrm{CaCd}$
$\mathrm{Ca}$
$\mathrm{Cd}$
$\mathrm{MgZn}$
$\mathrm{Mg}$
$\mathrm{Zn}$

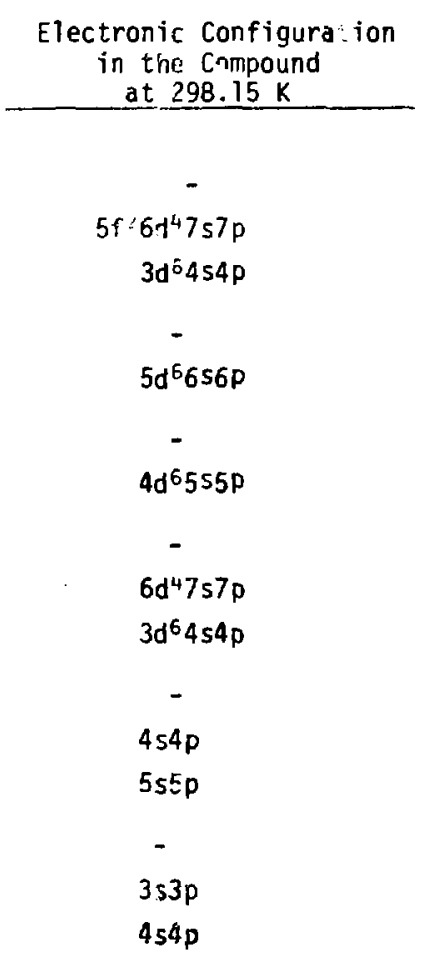

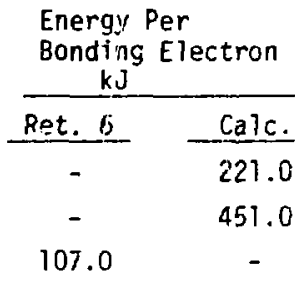

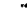

269.0

178.0

- 261.0

- 167.0

$-\quad 215.0$
$-\quad 0210$

431.0

107.0

$217.0 \quad 217.0$

178.0

236.5

$24 \mathrm{~J} .0$

240.0

2.03 .0

258.0 
C. Cohesive Energies for Correlated Group III Compounds

The two compounds $\mathrm{CaCd}_{2}$ and $\mathrm{Mgin}_{2}$ in this group have known cohesive energies ard electronic corfigurations. The line joining the $E_{c o h}$ values in Table III is

$$
E_{\text {coh }}=480.7-209.6 R_{A} / R_{B} k J / e l e c t r o n
$$

and $E_{\text {coh }}^{1}=223.9$ which from Equation 8 gives $-\Delta H_{i 298}^{l}=43.2$. When 2 iine is drawn between this value and $\Delta H_{f_{298}}=0$ at $K_{A} j R_{B}=1.7$ the result. is described by

$$
-\Delta H_{f_{298}}^{O}=-379.9+345.36 R_{A} / R_{B} \quad k \cdot J / g-\text { atom }
$$

from which $\Delta H_{f_{238}}^{0}$ for $\mathrm{CaCd}_{2}$ can be calculated. The line between this point and $\Delta H_{f_{298}}^{O}=0$ at $R_{A} / R_{B}=1.44$ is

$$
-\Delta H_{f_{298}}^{0}=289.13-200 R_{A} / R_{B} k J / g \text {-atom }
$$

from which $\Delta H_{f_{298}}^{0}$ for $\mathrm{CaCd}_{2}$ can be calcuilated.

D. Cohesive Energies for Correlated Group IV Compounds

Promotion energies ${ }^{7}$ for the trivalent $\mathrm{Ce}$, and $\mathrm{Pu}$, and cohesive energies ${ }^{6}$ for $\mathrm{Vb}$ and $A 1$ are given by Brewer.

As war the case wi in the compound $\mathrm{NaCd}_{2}$ the cohesive energy per electron for these metals alloved with Al must be increasea by $\Delta H_{+}^{3}$ to be on the line joining $\mathrm{LaAl}_{2}$ and $\mathrm{PrAl}_{2}$. The line is given by

$$
E_{\text {coh }}=741.1-389.1 R_{A} / R_{B} \text { kJ/electron . }
$$

The cohesive energies of this group of compounds couple with the size adjustment energies $\Delta H_{f}^{2}$ to form a line terminating at $E_{\text {coh }}^{1}=264.5$ giving $-\Delta H_{f}^{1}=83.8$ and passing through a point where $\Delta H_{f}^{I}=0$ at $R_{A} / R_{B}=1.44$ which is identical to the $\Delta H_{f_{298}}^{0}$ vs $R_{A} / R_{B}$ ? ine for this group.

The cohesive energies and electronic configurations are given in Tahie IV. 
TAB!: E IV

ELECTRONIC CONFIGURATION AND COHESIVE ENERGIES IN THE GÄSEUUS

VALENCE STATE AT $\mathrm{K}$ FOR CORRELATED GROUP IV

\begin{tabular}{|c|c|c|c|}
\hline $\begin{array}{l}\text { Element or } \\
\text { Compound }\end{array}$ & \multirow[t]{2}{*}{$\begin{array}{l}\text { Eiectronic Configuration } \\
\text { in the Compourd } \\
\text { at } 298.15 \mathrm{~K} \\
\end{array}$} & \multicolumn{2}{|c|}{$\begin{array}{l}\text { Energy Per } \\
\text { Bonding Electron }\end{array}$} \\
\hline & & kets. $0, f$ & 2350 \\
\hline $\mathrm{Ce} \mathrm{Al}_{2}$ & & 235.0 & 235.0 \\
\hline $\mathrm{Ce}$ & $4 f 6 s 60^{2}$ & 258.0 & 258.0 \\
\hline AT & $3 s 3 p^{2}$ & 224.0 & - \\
\hline $\mathrm{LaAi}_{2}$ & - & - & 231.0 \\
\hline La & $6 s 6 p^{2}$ & - & 246.0 \\
\hline $\mathrm{PrAl}_{2}$ & & - & 244.0 \\
\hline $\mathrm{Pr}$ & $4 f^{2} 6 s 6 p^{2}$ & - & 285.0 \\
\hline$P: A]_{2}$ & & 228.0 & 229.0 \\
\hline $\mathrm{Pu}$ & $5 f^{5} 7 s 7 p^{2}$ & 235.0 & 239.0 \\
\hline$U A I_{2}$ & - & - & 212.0 \\
\hline$U$ & $5 f^{3} 7 s 7 p^{2}$ & - & 188.0 \\
\hline $\mathrm{YDA}_{2}$ & - & 210.0 & 206.0 \\
\hline YD & $4 f^{24} 6570$ & 187.0 & 171.0 \\
\hline
\end{tabular}

iv. SUMMARY

The purpose of this paper has been th show by example the energy relationships involved in change of valence, and the proportionality of cchesive energy per electron in the gaseous state to heats of formation, or transition at constant temperature in the sclid state. The heats of formation calculated from these relationships are compared to experimental values in Table I. There is very good agreement in ail cases with the exception of $\mathrm{CaCd}_{2}$ for which the selected value is too negative and should be redet, rmined. The latest value for the $\Delta H_{f_{298}}^{0}$ selected for $\mathrm{MgZn}_{2}$ by Hultgren et $\mathrm{a} 1 .,^{10}-10.9 \mathrm{~kJ} / \mathrm{g}$ atom, is too fositive. The value in Table I is from the work of Biltz. ${ }^{11}$

It has been noted in Figure 2 that the cohesive energy of the compounds as a function of $R_{A} / R_{B}$ forms straight lines all of which have negative slopes. This is undoubtedly the prime factor in causing the $\Delta H_{f_{298}}^{0}$ vs $R_{A} / R_{B}=1.225$ to be asymmetric around $R_{A} / R_{B}=1.225$.

The total conesive energy arrived at for $U$ in the case of $U A]_{2}$ is very close to the heat of vaporization if it is assumed that there are oniy three: electrons involved in bonding. Brewer ${ }^{6}$ has treated $f$ electron bonding separately from $d, p$ and $s$ bonding. It appears from this work that in the case of $U$ in $\mathrm{UAl}_{2}$ all electrons should be treated equally. Assigning a value of 6 boriding electrons, each having $188 \mathrm{~kJ}$ cohesive energy we find that the promotion energy 
for the $5 f^{3} 7 \mathrm{~s} 7 p^{2}$ configuration is $49.5 \times 10^{3} \mathrm{~cm}^{-1}$. Brewer gives 4 ! $\times 10^{3} \mathrm{~cm}^{-1}$ for the $f^{t} p^{2}$ corifiguration. The $f^{3} s p^{2}$ configuration is not given. There appears to be little $f$ electron bonding in $\mathrm{PuAl}_{2}$.

It is too soon to make an at.tempt to explain from first principles why cohesive energy per electron in the gas phase is proportional to heats of transition or formation per g-atom in the solid phase, or why energy exactly equivalent to the heat of fusion of olle g-atom of $A$ is involved in the change of valence of $A$ in one g-atom of $A B_{2}$.

\section{REFERENCES}

1. G. M. Campbel1, in 5th International Conference on Plutonium and Other Actinides 1975, ii. Blank and R. Linder, Eds. (North-Holland Publishing Co., Ams terdam, 197E), p. 95.

2. G. M. Campbe1?, Met. Trans. A, 8A, 1493 (1977).

3. W. H. Zachariasen, J. Inorg. Nuc 1. Chem. 35, 3,487 (1973).

4. K. H. J. Buschow, M. Brouha, H. J. van Daal and A. R. Miedema, in Valence Instabilities and Related Narrow-Band Phenomena, R. D. Parks, Ed. (FTenum Press, New York, 1977) p. 125.

5. A. Iandelli and A. Palenzona, J. Less Conmon Met. 29,293 (1972).

6. L. Brewer, Lawrence Berkeley Lab. Report, LBL 3720 (1975).

7. L. Brewer, J. Opt. Soc. Amer., 61,1101 (1971).

8. R. Hultgren, R. L. Or , P. D. Anderson and K. K. Kelley, Selected Values of Thermodynamic Properties of Metals and Alloys, (Wiley, Inc., New York, $1 \overrightarrow{963}$ ).

9. R. Hultgren, R. L. Orr K. K. Kelley, Supplement to Selected Values of Thermodynamic Properties of Metals and Alloys TUniversity of California, Berkeley, CA, 1970).

10. R. Huligren, P. D. Desai, D. T. Hawkins, M. Gleiser K. K. Kelley, Selected Values of the Thermodynamic Properties of Binary Alloys (American Society for Metals, Metals Park, Ohio, 1973).

11. W. Bilty, 2. Metallk., 29,73 (1973).

12. W. Bilty and H. Peiper, Z. Anorg. Allg. Chem. 134,13 (i924).

13. G. Canneri and A. Rossi, Gazz. Chim. Ita1, , 62,202 (1932).

14. G. Canneri and A. Rossi, Gazz. Chim. Ita?., 63,182 (1938). 
15. V. V. Akhachinskii, L. M. Kopytin, M. I. Ivanov N. S. Podol'skaga, in Thermodynamics of Nuclear Materials (IAEA, Vienna, 1962), p. 309.

16. P. Chiotti and J. A. Kateley, J. Nucl, Mat. 32,135 (1969).

17. A. Palenzona, S. Cirafici, G. Ba?ducci and G. Bard, Thermochimica Acta 23, 393 (1978).

18. W. Biltz and W. Wagner, Z. Anorg. Chem. 134, ? (1924).

19. R. C. King and 0. J. Kleppa, Acta Metallurgica 12,87 (1964). 